\title{
AS POLÍTICAS PÚBLICAS DE INCLUSÃO E A LÓGICA CLASSIFICATÓRIA ILUMINISTA ${ }^{1}$
}

Daniela Silva Costa Campos ${ }^{2}$

\section{RESUMO}

O termo "inclusão escolar" indica uma reestruturação no âmbito da educação especial, vinculada a uma discussão política mais ampla que vem sendo travada, desde a década de 1990, por organismos internacionais, acerca dos rumos a serem tomados pela educação. Através da exposição de tais políticas, que culminaram na elaboração das Diretrizes para Educação Especial na Educação Básica (MEc, 2001), o presente trabalho busca explicitar a afirmação de Skliar (1999) de que a lógica ali presente aproxima-se da lógica classificatória iluminista. A tentativa de absorver todos os discursos, toda a diferença é sintomática das políticas que subsidiam a chamada "educação para todos", como se com tais prescrições legais tivéssemos uma demarcação definitiva entre excluídos/incluídos.

Palavras-chave: inclusão, política pública, universidade, educação especial.

\section{INTRODUÇÃO}

O termo "inclusão escolar" tem sido utilizado no âmbito das políticas públicas em educação, especialmente desde a década de 1990, para caracterizar um enfoque em educação especial distinto do enfoque denominado "integração". Se neste último a ênfase recaía sobre o ajustamento da pessoa com deficiência para sua participação na escolarização regular, a política de inclusão postula uma

\footnotetext{
${ }^{1}$ Artigo recebido em 1/8/2003 e aprovado em 10/9/2003.

${ }^{2}$ Mestre em Educação Brasileira e Professora de Psicologia da Educação da UNIPAC-MG.

[e-mail: danicosta@uol.com.br]
} 
reestruturação do sistema educacional para que possa atender todos os alunos.

Pessoalmente, tive acesso às políticas de inclusão no ano de 2000, ano em que o estado de Goiás, pioneiro em sua implementação, lançou o "Programa estadual de educação para diversidade numa perspectiva inclusiva". Na época, trabalhava como psicóloga numa instituição escolar da rede regular e particular que atendia alunos que apresentavam características distintas do que se convencionou chamar "normalidade". O que caracterizava essa instituição não era o fato de atender todos os alunos que a buscassem, mas de acompanhar com proximidade a escolarização de cada um dos matriculados, juntamente com os pais e demais profissionais que, porventura, os acompanhassem fora da escola.

As teorias psicológicas adotadas eram as mesmas do ideário educativo contemporâneo, basicamente as teorias de Piaget e Vygotsky. Todavia, cada vez mais a psicanálise tornava-se uma referência para a compreensão dos processos de aquisição e resistência à aprendizagem, pelo fato de que tanto eu quanto a diretora da escola nos interessarmos por tal enfoque teórico.

A partir da concepção de inclusão explicitada nas referidas políticas, em minha dissertação de mestrado intitulada "Inclusão escolar e a (im)possibilidade de uma educação para todos" (2003), orientada pela profa. dra. Marília Gouvea de Miranda, da Universidade Federal de Goiás, busquei elaborar os processos que perfazem a inclusão do sujeito no âmbito educacional sob a ótica psicanalítica.

Partiu-se do pressuposto de que as políticas de inclusão, por um lado, enfatizam a obrigação da escola pública de aceitar, conter e trabalhar com a diversidade, por outro, parecem surgir num nível totalitário, sem deixar espaço para uma análise diferenciada dos efeitos das práticas inclusivas sobre cada sujeito. Ou seja, parecem desconsiderar o operador subjetivante que está implicado em todo ato educativo, operador que apresenta-se no campo do Outro.

No presente trabalho, mais do que a realização de uma síntese dessa pesquisa, trar-se-á dados da análise das atuais políticas inclusivas no Brasil contidos em um dos capítulos, que permitiu a aproximação da lógica ali presente à lógica classificatória iluminista. 
Iluminismo que, de fato, postula o insofismável direito à igualdade, mas que tem, como uma de suas conseqüências, a suspensão da dialética sujeito/história, ao postular uma auto-regulação natural no indivíduo entre seu desejo e os cânones legais em vigor. ${ }^{3}$

\section{A POLÍTICA INCLUSIVISTA NO BRASIL}

O termo 'inclusão', apesar de ser bastante amplo e representar demandas históricas de vários segmentos, nos parâmetros educacionais atuais restringe-se às políticas que postulam a inclusão de alunos com necessidades educacionais especiais na rede regular de ensino.

Um marco decisivo de tal proposta política é a "Conferência Mundial sobre Necessidades Educacionais Especiais: Acesso e Qualidade", realizada em 1994 em Salamanca, organizada pela Unesco e pelo Banco Mundial. A Declaração de Salamanca (2001), que relata a referida conferência, afirma que as mudanças requeridas para a educação inclusiva não se relacionam exclusivamente aos educandos com necessidades educacionais especiais e que seus objetivos são os mesmos da "educação para todos" promulgados pela Conferência Mundial de Jomtien (1990), organizada pelas mesmas instituições internacionais da conferência mencionada acima.

Os documentos oficiais no Brasil passaram a colocar, objetivamente, a educação especial no contexto da educação regular a partir da Constituição de 1988. Todavia, tanto nesse documento quanto na LDB n. 9.394/96 o termo utilizado é "integração" e não "inclusão".

O documento mais atual - que institui as Diretrizes para a Educação Especial na Educação Básica (MEc, 2001) - revê imprecisões terminológicas presentes na LDB, no que tange à inclusão, imprecisões que foram apontadas pelos partidários da proposta, já que deixavam brechas para que as instituições se eximissem de aceitar todo e qualquer aluno e também para que o Estado se eximisse de patrocinar essa inclusão na rede pública de ensino.

A LDB institui que o atendimento às crianças com necessidades educacionais especiais deve realizar-se "preferencialmente" na rede regular e que haverá apoio especializado "só quando necessário". Também prevê que tal apoio pode ficar sob o encargo das instituições 
privadas sem fins lucrativos, já que tal modalidade de educação especial é dever do Estado, desde que oferecida preferencialmente na rede regular de ensino. De acordo com a Resolução CNE/CEB n. 02/2001:

Art. 2 - Os sistemas de ensino devem matricular todos (grifo meu) os alunos, cabendo às escolas organizar-se para o atendimento dos educandos com necessidades educacionais especiais, assegurando (grifo meu) as condições necessárias para uma educação de qualidade para todos (p. 69).

Institui ainda que as escolas da rede regular de ensino devem prever e prover, na organização de suas classes comuns, além de professores capacitados para atuar com alunos que apresentem necessidades educacionais especiais e flexibilizações e adaptações curriculares, serviços de apoio pedagógico especializado, mediante:

1 - Atuação colaborativa de professor especializado em educação especial;

2 - Atuação de professores-intérpretes das linguagens e códigos aplicáveis;

3 - Atuação de professores e outros profissionais itinerantes intra e interinstitucionalmente;

4 - Disponibilização de outros apoios necessários à aprendizagem, à locomoção e à comunicação;

5 - Serviços de apoio pedagógico especializado em salas de recursos, nas quais o professor especializado em educação especial realize a complementação ou suplementação curricular, utilizando procedimentos, equipamentos e materiais específicos (p. 71-72).

Na historização da educação especial proposta por Bueno (2001), a proposta inclusivista se situa numa etapa que se inicia na década de 1960, caracterizada pela expansão do poder público no âmbito da educação especial e pela ampliação das sintomatologias caracterizadas como especiais. Sustenta que essa ampliação, além de incluir os quadros patológicos de fundo neurológico antes não 
detectáveis, foi incorporando uma população com deficiências e distúrbios cada vez mais próximos da normalidade entendida como média.

Dentro desse momento é preciso distinguir uma etapa consensualmente denominada de "integração", quando as políticas incentivavam que as escolas regulares recebessem um número cada vez maior de crianças provenientes da educação especial, desde que essas crianças apresentassem condições mínimas de adaptação. Por definição, a política de integração previa que eram as crianças que deveriam se adaptar às escolas, ao contrário do que postula a política de inclusão, assim definida pelas diretrizes:

Representando um avanço em relação ao movimento de integração escolar, que pressupunha o ajustamento da pessoa com deficiência para sua participação no processo educativo desenvolvido nas escolas comuns, a inclusão postula uma reestruturação do sistema educacional, ou seja, uma mudança estrutural no ensino regular, cujo objetivo é fazer com que a escola se torne inclusiva, um espaço democrático e competente para trabalhar com todos os educandos, sem distinção de raça, classe, gênero ou características pessoais, baseando-se no princípio de que a diversidade deve não somente ser aceita como desejada (p. 40).

As diretrizes (2001) contemplam que tornar realidade a educação inclusiva não se efetuará somente por decreto, mas apostam que o momento denominado de "integração" já fora superado, pois impedia que a maioria com necessidades especiais alcançasse os níveis mais elevados de ensino. Afirma-se que "a ruptura com a ideologia da exclusão proporcionou a implantação da política de inclusão, que vem sendo debatida e exercitada em vários países, entre eles o Brasil" (p. 21).

Compreendem educação inclusiva como um "novo fazer pedagógico", um "novo momento", uma "nova leitura" sobre a educação do cidadão, "nova abordagem" que deverá vincular suas ações cada vez mais à qualidade da relação pedagógica e não apenas a um público-alvo delimitado, "de modo que a atenção especial se faça presente para todos os educandos que, em qualquer etapa ou 
modalidade da educação básica, dela necessitarem para seu sucesso escolar" (p. 45-46).

A ênfase no "novo" transparece pela afirmação de que vivenciamos uma nova era, a "era dos direitos" (p. 21), em que o principal direito refere-se à preservação da dignidade e à busca da identidade como cidadãos. De fato, apesar desses direitos básicos estarem legislados, no Brasil e no mundo, há mais de um século, o fracasso de sua efetivação é também amplamente conhecido.

Ancorado nesse fracasso, verifica-se, desde a década de 1990, políticas sociais "reformadoras" promovidas por organismos internacionais, especialmente pelo Banco Mundial e pela Unesco. Segundo Popkewitz (1998) é em nome do progresso que o discurso educacional vincula as racionalidades políticas da democracia liberal às estratégias solucionadoras de problemas que surgem como reforma. Todavia, "Sua inscrição ocorre na medida em que a idéia de progresso social é individualizada como administração social da alma [...] no sentido de reger as subjetividades da criança” (p. 147).

Popkewitz (1998) afirma ainda que os princípios regentes da reforma não são explícitos, mas encontram-se inscritos nessa concepção de uma "nova" criança e de um "novo" professor, o qual passa a funcionar como agente redentor. Agente do empreendimento da educação como redentora, ou seja, como principal propulsora de eqüidade social.

O processo de reforma culminou na realização das duas conferências mundiais anteriormente citadas. Entretanto, analistas dos parâmetros da "educação para todos" reiteram que, apesar da palavrachave do discurso da chamada reforma ser "eqüidade",

as incoerências do discurso patenteiam que se a proposta acena para a integração social dos sujeitos, na prática o Estado realiza um projeto educacional excludente. Afinal, contra-sensos no plano formal não precisam ser resolvidos, posto que não afetam a implementação do projeto real. (SHIROMA, 2000, p. 113)

Coraggio (1996), ao analisar o documento elaborado exclusivamente pelo Banco Mundial acerca da Conferência Mundial de Jomtien, afirma que seu principal objetivo é a manutenção de um 
cenário de certa estabilidade, incompatível com quadros de pobreza e analfabetismo, para se angariar investimentos. Apesar do discurso apresentar-se como uma questão de eqüidade social, o principal objetivo do banco é o ataque à pobreza (p. 85).

Já o relatório Delors, "Educação - um tesouro a descobrir" (2000), que apresenta a visão específica da Unesco baseada na mesma conferência, tem um tom mais humanístico que os documentos do banco, ainda assim não enfatiza as condições concretas para a eqüidade com qualidade. $\mathrm{O}$ que prevalece no relatório Delors é o compromisso com o "acesso" da população a níveis cada vez mais elevados de escolarização, dando ênfase àqueles historicamente excluídos das classes regulares: os mais pobres, a população rural, as diversas etnias ou os grupos culturais, o gênero feminino, jovens e adultos não alfabetizados. A qualidade da inclusão é secundarizada, já que as condições concretas para atender à diversidade são tratadas hipotética e superficialmente (os grifos são meus):

Pode-se pensar na organização de grupos de apoio em todos os estabelecimentos de ensino: criar recursos de aprendizagem mais suaves e flexíveis para os alunos que tiverem menos adaptados ao sistema escolar e que devem ser dotados para outros tipos de atividades. O que supõe, em particular, ritmos especiais de ensino e turmas reduzidas. (DELORS, 2000, p. 147)

Em tese, o texto que veicula a proposta de "educação para todos" (Delors, 1996) também propaga uma proposta inclusiva em educação. Promulga as políticas educativas como "um processo permanente de enriquecimento dos conhecimentos, do saber-fazer, mas também, e talvez em primeiro lugar, como uma via privilegiada de construção da própria pessoa, das relações entre indivíduos, grupos e nações" (p. 12). Todavia, passadas as primeiras páginas, a ênfase no cognitivismo e na instrumentalização do conhecimento ficam evidentes:

É que, se é verdade que cada um deve utilizar todas as possibilidades de aprender e de se aperfeiçoar, não é menos verdade que para estar apto a utilizar, corretamente, estas 
potencialidades, o indivíduo deve estar na posse de todos os elementos de uma educação básica de qualidade (p. 18).

Posse e domínio cognitivo são conceitos-chave no contexto do que a reforma espera de uma educação básica; inicialmente, esse domínio serviria para atender às novas demandas mercadológicas; posteriormente, as citações apontam para uma onipotência ainda maior, de domínio das rápidas transformações científicas: "A educação tem, sem dúvida, um papel importante a desempenhar se quiser dominar o desenvolvimento do entrecruzar de redes de comunicação" (DELORS, 1996, p. 40). Com o suposto "domínio" das tecnologias que realizam a exploração indiscriminada de bens naturais ficar-se-ia imune a seus riscos.

Além de considerar o conhecimento como instrumento para se atingir o domínio de determinadas habilidades que atendam ao mercado de trabalho, o relatório insiste na organização e formalização do saber:

A responsabilidade dos sistemas educativos surge em primeiro plano: cabe-lhes fornecer, a todos, meios para dominar a proliferação de informações, de as selecionar e hierarquizar, dando mostras de espírito crítico (p. 66).

Numa última e mais onipotente de todas as citações que envolvem a dimensão do "domínio" da esfera cognitiva do saber, podese ponderar que sua insistência não é mera inapropriação do conceito, mas é sintomática, repetição de uma lógica que não quer calar:

Um dos principais papéis reservados à educação consiste, antes de mais nada, em dotar a humanidade da capacidade de dominar o seu próprio desenvolvimento. (DELORs, 1996, p. 82)

Numa perspectiva dialética do conhecimento, quando se fala da construção do saber, este não se restringe à dimensão cognitiva, aquela relacionada à solução de problemas formais escolares, mas abrange também a esfera simbólica, aquela que diz respeito à forma singular com que cada sujeito apropria-se desse saber formal. Portanto, mesmo que o sujeito apresente um comprometimento na capacidade de simbolizar, a esfera do saber é sempre perpassada por algo que é 
da ordem da singularidade, o que faz com que seja um saber sempre em construção, constantemente atualizado, cujos efeitos não podem ser controlados e só podem ser conhecidos a posteriori.

A Declaração de Salamanca, apesar de afirmar que seus princípios são os mesmos da Conferência de Jomtien, fundamentalmente, o de eqüidade com qualidade, apresenta-se menos voltada para os aspectos meramente cognitivos de construção do saber e traz afirmações que dão margem para se considerar a inclusão simbólica do sujeito, na medida em que ressalta as condições concretas para se incluir a diversidade:

O desenvolvimento de escolas inclusivas que ofereçam serviços a uma grande variedade de alunos em ambas as áreas rurais e urbanas requer a articulação de uma política clara e forte de inclusão junto com provisão financeira adequada - um esforço eficaz de informação pública para combater o preconceito e criar atitudes informadas e positivas - um programa extensivo de orientação e treinamento profissional - e a provisão de serviços de apoio necessários. Mudanças em todos os seguintes aspectos da escolarização, assim como em muitos outros, são necessárias para a contribuição de escolas inclusivas bem-sucedidas: prédios, organização escolar, pedagogia, avaliação, pessoal, filosofia da escola e atividades extra-escolares. (UNESCO, 2001)

Skliar (1999) ressalta, todavia, a vinculação do discurso da Declaração de Salamanca ao discurso progressista reformador. Afirma que o discurso da escola inclusiva presente nesse documento parece operar pelo menos em dois níveis diferenciados:

por um lado, em um nível supostamente progressista, a partir do qual se denunciam as formas terríveis e temíveis de discriminação e exclusão das escolas especiais; descrevem-se as práticas pedagógicas absurdas [...]; fala-se da obrigação da escola pública de aceitar, conter e trabalhar com a diversidade, etc. Porém, por outro lado, parece surgir um nível totalitário, através do qual continua reproduzindo-se o contínuo de sujeitos deficientes sem deixar espaço para uma análise diferenciada dos processos e dos efeitos de tais práticas para/sobre cada um deles; todo e 
qualquer argumento crítico [...] é rapidamente censurado, considerado politicamente incorreto (p. 25-26).

De fato, apesar dos avanços que podem ser encontrados nessa declaração quanto aos investimentos materiais e humanos que devem ser dispensados à efetivação da proposta inclusiva, a caracterização dos sujeitos com "necessidades educacionais especiais" é bastante inespecífica, pois refere-se a "todas aquelas crianças ou jovens cujas necessidades educacionais especiais se originam em função de deficiências ou dificuldades de aprendizagem" (UNESCO, 2001, p. 4). A certa altura do texto, há a observação de que "Atenção especial deve ser prestada às necessidades das crianças e jovens com deficiências múltiplas ou severas" (p. 9).

A definição trazida pelas Diretrizes Nacionais para a Educação Especial na Educação Básica (MEc, 2001) é um pouco mais específica. Educandos que apresentam necessidades educacionais especiais são aqueles que, durante o processo educacional, demonstram:

2.1 - dificuldades acentuadas de aprendizagem ou limitações no processo de desenvolvimento que dificultem o acompanhamento das atividades curriculares, compreendidas em dois grupos:

2.1.1 - aquelas não vinculadas a uma causa orgânica específica;

2.1.2 - aquelas relacionadas a condições, disfunções, limitações ou deficiências;

2.2 - dificuldades de comunicação e sinalização diferenciadas dos demais alunos, demandando adaptações de acesso ao currículo, com utilização de linguagens e códigos aplicáveis;

2.3 - altas habilidades/superdotação, grande facilidade de aprendizagem que os leve a dominar rapidamente os conceitos, os procedimentos e as atitudes e que, por terem condições de aprofundar e enriquecer esses conteúdos, devem receber desafios suplementares em classe comum, em sala de recursos ou em outros espaços definidos pelos sistemas de ensino, inclusive para concluir, em menor tempo, a série ou etapa escolar (p. 39). 
Entretanto, trata pormenorizadamente apenas das necessidades especiais, abaixo descritas (p. 44-45):

1 - Dificuldades de comunicação e sinalização diferenciadas dos demais alunos, particularmente os que apresentam surdez, cegueira ou distúrbios acentuados de linguagem;

2 - Condições específicas associadas à surdez, à cegueira e à visão subnormal;

3 - Altas habilidades/superdotação.

Menciona especificamente as condutas típicas de síndromes e quadros psicológicos, neurológicos ou psiquiátricos, e alunos que apresentam casos graves de deficiência mental ou múltipla, somente ao se referir à possibilidade de manutenção da educação especial ou à existência de classes especiais no ensino regular.

Quanto aos critérios para abertura de uma classe especial, as diretrizes afirmam que esta pode ser utilizada, em caráter transitório, por "alunos que apresentem dificuldades acentuadas de aprendizagem ou condições de comunicação e sinalização diferenciadas dos demais alunos e demandem ajudas e apoios intensos e contínuos" (p. 52), principalmente, nas localidades em que não há oferta de educação especial. Considera também que não se deve compor uma classe especial com alunos que

apresentem dificuldades de aprendizagem não vinculadas a uma causa orgânica específica, tampouco, se deve agrupar alunos com necessidades especiais relacionadas a diferentes deficiências (p. 53).

De fato, as diretrizes, em concordância com a Declaração de Salamanca, não postulam a extinção da educação especial que deve atender àqueles alunos que

requeiram atenção individualizada nas atividades da vida autônoma e social, bem como ajudas e apoios intensos e contínuos e flexibilizações e adaptações curriculares tão significativas que a escola comum não tenha condição de prover (p.54). 
E tanto neste quanto no caso da abertura de classes especiais, a decisão é perpassada pela questão do diagnóstico.

Pode-se depreender dos textos que veiculam proposta inclusiva que o foco das atenções deve-se deslocar da deficiência da pessoa, da busca, no aluno, da origem do problema, e centrar-se no ensino, na escola, nos recursos e apoios que a escola deve proporcionar ao aluno para que este tenha sucesso. As diretrizes (2001, p. 34) trazem a determinação de que se deve realizar, no decorrer do processo educativo, uma avaliação pedagógica dos alunos que apresentem necessidades educacionais especiais, objetivando identificar as barreiras que estejam impedindo ou dificultando o processo educativo.

Sob esse enfoque, ao contrário do modelo clínico, tradicional e classificatório, a ênfase deverá recair no desenvolvimento e na aprendizagem do aluno, bem como na melhoria da instituição escolar, onde a avaliação é entendida como processo permanente da análise das variáveis que interferem no processo de ensino e aprendizagem, para identificar potencialidades e necessidades educacionais dos alunos e as condições da escola para responder a essas necessidades (Mec, 2001, p. 34). Define como modelo clínico tradicional aquele que se detinha no que pretensamente "faltava" aos educandos.

O papel dos serviços de apoio especializados previstos para a proposta inclusiva não diz respeito a essa avaliação, pois seu papel é o de atendimento às necessidades educacionais detectadas que podem ser realizadas tanto nas classes comuns quanto em salas de recursos. Para a realização de tais avaliações, a escola poderá recorrer a uma equipe multiprofissional.

Cabe aos gestores educacionais buscar essa equipe multiprofissional em outra escola ou sistema educacional ou na comunidade, o que pode se concretizar por meio de parcerias e convênios entre a Secretaria de Educação e outros órgãos, governamentais ou não (p. 35).

Bueno (1983) já denunciara o risco de se chegar "ao absurdo de se negar a existência de defeitos e anomalias que são evidentes aos nossos olhos" (p. 46), ao se refutar determinadas práticas por serem positivistas. Vê-se que, ao denunciar um modelo eminentemente 
clínico de diagnóstico, as diretrizes que postulam a educação inclusiva relegam o diagnóstico profissional a um segundo plano e podem incorrer mesmo na negação dos aspectos individuais presentes nas sintomatologias manifestas e, no limite, das próprias diferenças.

O conhecimento de que, historicamente, observam-se "dados imprecisos de avaliação e diagnóstico, além de erros grosseiros que denunciam a falta de critérios rigorosos para tal avaliação" (MENA, 2000, p. 33-34), no encaminhamento dos alunos para o ensino especial, não deve ser apoio para se relativizar tal procedimento numa prática inclusiva.

Ao postular que, no que tange às classes especiais, diferentes deficiências não devem estar juntas, a proposta também demonstra fragilidade. Por um lado, a inclusão é defendida mesmo sem o conhecimento profissional das diversas sintomatologias apresentadas pelos alunos; por outro, ao se deduzir que determinado aluno demanda condições específicas de aprendizagem, este deve ser agrupado somente com aqueles que apresentem dificuldades nas mesmas áreas, ou seja, com seus "iguais".

De fato, as sintomatologias mais facilmente detectáveis são aquelas que merecem destaque nas especificações quanto ao apoio material e humano necessário a uma educação de qualidade, a saber, deficientes visuais, auditivos e superdotados. Não por acaso, são sintomatologias que, em geral, não são acompanhadas dos chamados "déficts de inteligência", muito pelo contrário no que tange aos superdotados.

O governo do estado de Goiás, pioneiro no Brasil no sentido de adotar a proposta inclusiva em seu plano de governo, cujo processo chamado "sensibilização" iniciou-se em 1999, lançou um levantamento (em agosto de 2002) realizado junto às 325 unidades inclusivas do estado acerca das sintomatologias encontradas nessas unidades. Segundo Renata Tavares, ${ }^{4}$ coordenadora de um dos departamentos de ações institucionais da Superintendência de Ensino Especial da Secretaria de Educação do Estado de Goiás, dentro do número total de alunos com necessidades educacionais especiais encontrados, foram especificados somente a deficiência visual, auditiva, mental e múltipla (de diagnóstico mais evidente). Já as condutas típicas, as 
síndromes e as dificuldades de aprendizagem e de comportamento são colocadas na categoria “outros", pela dificuldade diagnóstica.

A entrevistada relata que para o investimento em diagnóstico as subsecretarias recebem uma verba da secretaria que precisa ser reforçada por uma verba dos municípios. Portanto, tanto mais criterioso o diagnóstico quanto mais verbas os municípios se dispuserem a investir.

O Programa de Educação Inclusiva do Estado de Goiás, denominado "Programa estadual de educação para a diversidade numa perspectiva inclusiva", é composto por dez projetos que englobam a adaptação física e curricular das escolas, a capacitação dos professores, o trabalho com as famílias, o atendimento educacional hospitalar, o atendimento aos autistas, a municipalização da escola inclusiva, o uso de todos os recursos comunicativos (inclusive a língua de sinais), o atendimento a alunos com altas habilidades, a inclusão pela arte e a prevenção e detecção de deficiências. Atualmente, o Estado conta com 325 escolas chamadas de referência no projeto, sendo 34 localizadas na capital. Foram realizadas reformas no espaço físico de 111 dessas escolas, no sentido de extinguir-se as barreiras longitudinais, e foi aprovada uma lei para que, doravante, somente se autorize a construção de escolas que correspondam às exigências físicas para a inclusão.

Desde o lançamento do programa em outubro de 2000, realizamse permanentes cursos de capacitação para os professores das unidades inclusivas, assim como braile e sorobã para os municípios que os solicitarem. O livro considerado referência para subsidiar a capacitação é o organizado por Stainback e Stainback Inclusão um guia para educadores (1999), além do material produzido por Romeu Kazumi Sassaki, consultor em inclusão social e autor do livro Inclusão: construindo uma sociedade para todos (1999).

A análise desse material é reveladora do aspecto totalitário presente no discurso oficial da escola inclusiva, discurso em que "a diferença passa a ser definida como diversidade que é entendida quase sempre como a/s variante/s aceitáveis e respeitáveis do projeto hegemônico da normalidade" (SKLIAR, 1999, p. 21). O citado autor denuncia ainda que a crescente atenção voltada para a educação 
especial, tanto no âmbito da medicina quanto no da pesquisa etnográfica, "não conduz, necessariamente, a uma ruptura da hegemonia do homem branco, masculino, bem alimentado, letrado, profissional, saudável, etc" (p. 20).

Stainback e Stainback (1999) trazem uma afirmação de Wehman (1990, p. 43) de que "as turmas segregadas não conduzem à independência e à competência, mas estimulam uma sensação irrealista de isolamento" (p. 24). Complementam que, em contraste, no ensino inclusivo, "Os alunos com deficiência aprendem como atuar e interagir com seus pares no mundo real" (p. 25). Como se vê nessas citações, é como se desejar menos segregação implicasse necessariamente em negação da "realidade" da deficiência, tendo como referência padrões de competência exigidos pela sociedade capitalista.

Ao apresentar a "fala" da mãe de uma criança portadora de necessidades especiais, o citado texto reitera a ênfase nas "competências":

Nossa filha, Shawntell, não vai acordar com todas as competências e habilidades de que necessita para viver independentemente [...]. Mas imagine se ela conseguisse dominar todas essas competências, fizesse todas essas coisas perfeitamente? (p. 234)

Mesmo tentando não distinguir as crianças em alunos de classes regulares e especiais, o texto pauta-se por ideais de perfeição e competência previamente delineados. Contradições dessa ordem continuam a aparecer:

O desafio mais difícil da avaliação em uma escola inclusiva, entretanto, é fundir a filosofia e as práticas de valorização das necessidades de aprendizagem de todas as crianças com uma expectativa de excelência [grifo meu] de aprendizagem igualmente valiosa (p. 264).

Além disto, o texto organizado por Stainback e Stainback é excessivamente prescritivo, revelando mais uma vez a tentativa de negação das diferenças. Apresenta listas e mais listas, como: "o que 
precisa acontecer para que as amizades se desenvolvam", "opções para facilitar o acesso dos alunos à aprendizagem", "como avaliar as inteligências múltiplas", "crenças necessárias para dar suporte à cultura compartilhada da inclusão", "sugestões de planejamento nas áreas de relacionamento entre o lar e a escola", "habilidades dos bons professores", "oito objetivos para um ensino multicultural", entre outras tantas.

O material elaborado por Sassaki caminha nessa mesma direção. Traz "Lista de checagem sobre as práticas inclusivas na sua escola", "Componentes e um plano estratégico de ação para a educação inclusiva", "Perguntas e respostas sobre educação inclusiva", "Nove tipos de adaptações", "Terminologia sobre deficiência na era da inclusão" e outros textos que explicitam a Declaração de Salamanca, bem como apresenta modelos de escolas inclusivas de outros países.

De fato, tanto no discurso presente nas diretrizes quanto nesse material mantém-se o que Bhabha apud Skliar (1999) denomina de "lógica binária de oposições", como se, com tais prescrições legais e teóricas, tivéssemos uma demarcação definitiva entre os processos de inclusão/exclusão, a qual, para realizar a inclusão efetiva de todos os alunos, bastaria colocar em prática as estratégias prescritas, adaptar os métodos de ensino às características individuais, sem considerar os processos de produção e reprodução social.

Nas diretrizes, a afirmação de que a consolidação da prática inclusiva é mera questão de "tempo" pode ser vislumbrada na reiteração da expressão "ainda" (os grifos são meus):

Ainda hoje, constata-se a dificuldade de aceitação do diferente no seio familiar e social, principalmente do portador de deficiências múltiplas e graves, que na escolarização apresenta dificuldades acentuadas de aprendizagem (p. 19).

[...] ainda há momentos de séria rejeição ao outro, ao diferente, impedindo-o de sentir-se, de perceber-se e de respeitar-se como pessoa (p. 25).

A inclusão escolar constitui uma proposta que representa valores simbólicos importantes [...] mas encontra ainda sérias resistências (p. 26). 
Por mais que as políticas considerem, formalmente, os processos históricos de exclusão, supõem uma possível superação dos embates concernentes a seus efeitos. Afora a propaganda de que os fundamentos da educação inclusiva tratam-se de uma "novidade", o que se afirma é o velho e bom direito à igualdade reforçado, principalmente, pela garantia de condições materiais e de espaço físico diversificados.

Todavia, as condições humanas e afetivas que perpassam a escolarização e todo o convívio social das crianças que se distinguem de maneira significativa dos padrões historicamente construídos acerca da normalidade não são devidamente discutidos. É preciso afirmar com Bueno (1983), Mazzotta (1996) e Skliar (1999) que as políticas que postulam uma "educação para todos" desconsideram os processos sócio-históricos que determinam os processos de exclusão.

\section{A LÓGICA CLASSIFICATÓRIA ILUMINISTA}

Pode-se afirmar com Foucault (1999) que nem sempre os limites entre o normal e o patológico, entre o estranho e o familiar foram tão rigidamente estabelecidos como vislumbramos na consolidação de uma educação especial.

Sabe-se que, para que algum saber pudesse ser constituído sobre o sujeito, fora necessária a exclusão definitiva desse "estranho" do campo da linguagem, exclusão do vínculo direto do homem à sua causalidade. Coincide com um tempo histórico em que fora necessária a morte simbólica do pai para que os "filhos" pudessem partilhar os bens culturais, possibilitando o fortalecimento da razão para discernir.

Trata-se da Era Clássica que tem em Descartes seu principal expoente no que tange às novas possibilidades de conhecimento humano. O corte epistemológico realizado pelo filósofo inaugura a noção de um sujeito purificado de toda intenção preliminar de significação, ao negar que o homem seja o fim último da criação, a mais perfeita obra de Deus, como afirmava o pensamento medieval. Subtraído, então, de toda possibilidade de identificação imaginária com 
um ser supremo, o sujeito da ciência torna-se o fator determinado e não mais determinante das ações por ele realizadas.

Kant, um dos principais filósofos do Iluminismo, teoriza acerca de uma ética tributária ao advento do sujeito da ciência. Supõe a existência mítica de um paraíso perdido, anterior ao advento civilizatório, para postular a existência de um bem supremo que viesse restabelecer um modo de vida cuja regularidade nada deve à existência de regras. Para o autor, a relação entre razão e liberdade expressase pelo conceito de vontade, identificada com a vontade de fazer o bem. Apóia-se na idéia natural da justa medida da conduta humana que regularia o desejo (compreendido como o instinto primitivo do humano) e a vontade.

Teixeira (1999) ressalta que, por mais que do ponto de vista da moral e da tradição Descartes sustente uma figura de ascendência como causadora das determinações do sujeito, o cartesianismo teve, por conseqüência, a emergência de um sujeito vazio, destituído de todo atributo anterior a sua afirmação, a partir da concepção de uma organização natural do mundo firmada com o Iluminismo.

Seria forçoso afirmar que a ética presente nos parâmetros atuais de educação para todos é a mesma formulada pelo Iluminismo, mas sabe-se que, por mais que os esforços iluministas fossem ao encontro da uniformização da lei de igualdade, triunfa a substituição do homem singular pelo cálculo político do máximo de felicidade ao maior número de cidadãos. Além disso, determinantes classificatórias do sujeito, cada vez mais definidas, são construídas sob a justificativa de tal representação política.

As políticas inclusivistas, além de afirmarem textualmente que estamos vivenciando uma "Nova Era", a "Era dos Direitos", assim como postulava-se no Iluminismo, parecem basear-se numa lógica classificatória que separa "hipotéticos incluídos de hipotéticos excluídos" (SKLIAR, 1999, p. 35).

\section{CONSIDERAÇÕES FINAIS}

As políticas públicas em educação especial, atualmente denominadas políticas de "inclusão", asseveram as marcas físicas e 
psíquicas que perfazem um grupo particular de excluídos, os "educandos com necessidades educacionais especiais", e prevêem investimentos em insumos materiais, espaço físico adequado e na contratação de profissionais da área de saúde e da comunicação para auxiliarem a inclusão dessa população em escolas regulares.

De fato, tais investimentos são imprescindíveis para possibilitar uma educação de qualidade para os sujeitos que trazem no corpo uma marca real de exclusão. Contudo, percebe-se na formalização das políticas de inclusão a ampliação da população abarcada pelo citado grupo, incluindo-se alunos com dificuldades de aprendizagem ou de minorias raciais, o que acaba por anular tais particularidades.

As políticas também consideram as determinantes históricas que se sobrepõem às marcas singulares dos sujeitos com necessidades especiais, mas também o fazem com a suposição de que estamos vivenciando uma "Nova Era" e de que se aproxima o momento de superação definitiva dos processos de exclusão social.

Ou seja, ora desconsideram o que há de particular na compreensão dos processos de inclusão/exclusão, ora o que há de historicamente determinado. Mantêm uma lógica que pode ser considerada totalitária pela suspensão da dialética sujeito/história, ao vincularem a concepção de inclusão do sujeito na cultura às competências exigidas para o cidadão deste século, em que o saber é concebido como um instrumento de domínio do próprio destino.

Por mais que as políticas inclusivistas enfatizem a importância da valorização da diversidade, o estudo do material utilizado para a formação de professores para a prática inclusiva pauta-se, fundamentalmente, na prescrição de fórmulas a serem executadas, bem como em exemplos comparativos entre uma população supostamente "normal" e outra "especial".

Mantém-se, como anuncia Skliar (1999), uma lógica binária que separa hipotéticos incluídos de hipotéticos excluídos, lógica pautada nos cânones iluministas. Ao privilegiar-se tal lógica suprime-se qualquer discussão acerca dos possíveis efeitos das práticas inclusivas sobre cada sujeito, assim como o que há de "incômodo" no enfrentamento da diferença. 


\section{ABSTRACT}

The term " school "inclusion indicates a restructuring in the scope of the special education, linked to a wider political discussion since the 1990's, by international organisms, concerning the directions taken by the education. Through exhibition of such politics, that culminated in elaboration of Guidelines for Special Education in Basic Education (MEC, 2001), the present work looks for explanation the statement of Skliar (1999), that the logic there present approaches of the logic classificatory iluminist. The attempt of absorbing all the speeches, all the difference is symptomatic of the politics that subsidize the call " education for everybody", as if with such legal prescriptions we had a definitive demarcation among excluded/ included.

\section{NOTAS}

3. O início da produção freudiana também não fica imune à elaboração iluminista de uma regulação natural entre o desejo humano e os parâmetros morais e legais em vigor. Freud elabora o conceito de sublimação como um mecanismo próprio de uma estruturação psíquica "saudável", já que atende aos paradigmas civilizatórios. Todavia, cada vez mais tal conceito (sublimação) se desenvolve na direção de algo que transgride o processo civilizatório.

4. Em entrevista realizada por Daniela Silva Costa Campos, em 12/09/2002, na Superintendência de Ensino Especial da Secretaria Estadual de Educação.

\section{REFERÊNCIAS}

BRASIL. CNE/CEB no ${ }^{-2}$. Resolução de 11 de setembro de 2001. Institui diretrizes nacionais para a educação especial na educação básica.

BRASIL. MEC. Lei n. 9.394, de 20 de dezembro de 1996. Lei de diretrizes e bases da educação nacional.

BRASIL. MEC; SEESP, 2001. Diretrizes nacionais para a educação especial na educação básica.

BUENO, José Geraldo Silveira. A produção social da identidade do anormal. In: FREITAS, M. C. (Org.). História social da infância. São Paulo: Cortez, 2001. 
Educação especial brasileira: integração/segregação do aluno diferente. São Paulo: EDUC/PUC, 1993.

CORAGGIO, José Luís. Propostas do Banco Mundial para a educação: sentido oculto ou problemas de concepção? In: TOMMASE, L. de; WARDE, M. J.; HADDAD, S. (Orgs.). O Banco Mundial e as políticas educacionais. São Paulo: Cortez, 1996.

DELORS, Jacques. Educação: um tesouro a descobrir. São Paulo: Cortez, Brasília, DF: MEC: Unesco, 1998.

FOUCAULT, Michel. História da loucura. São Paulo: Perspectiva, 1999.

MAZZOTTA, Marcos J. da Silveira. Educação especial no Brasil: história e políticas públicas. São Paulo: Cortez, 1996.

MENA, Luiz Fernando Belmonte. Inclusões e inclusões: a inclusão simbólica. Psicologia, Ciência e Profissão, 2000, 20(1): 30-39.

POPKEWITZ, Thomas, S. A administração da liberdade: a cultura redentora das ciências educacionais. In: WARDE, Miriam, J. (Org.). Novas políticas educacionais: críticas e perspectivas. São Paulo, Programa de Estudos Pósgraduados em Educação: História e Filosofia da Educação da Pontifícia Universidade Católica de São Paulo, 1998.

SASSAKI, Romeu K. Inclusão: construindo uma sociedade para todos. São Paulo: Editora 34, 1999.

SHIROMA, Eneida; MORAES, Maria Cecília; EVANGELISTA, Olinda. O que você precisa saber sobre política. Rio de Janeiro: DPIA, 2000.

SKLIAR, Carlos. A invenção e a exclusão da alteridade "deficiente" a partir dos significados da normalidade. Educação e Realidade, 24 (1):15-32. São Paulo, 1999.

STAINBACK, Susan; STAINBACK, William. Inclusão: um guia para educadores. Porto Alegre: Artes Médicas, 1999.

TEIXEIRA, Antônio M. R. O topos ético da psicanálise. Porto Alegre: EDIPUCRS, 1999.

UNESCO online 2001. Disponível em: <http://www.unesco.org.br/publica/ DocInternacionais/declarasalamanca.asp> Acesso em: 10 de agosto de 2001. 